\title{
Sergey Sukhanov, a Russian Physician in Professor Arthur Van Gehuchten's Lab - Based on Original 19th Century Documents
}

\author{
Alla A. Vein ${ }^{a} \quad G^{-}$eneviève Aubert ${ }^{b}$ \\ ${ }^{a}$ Department of Neurology, Leiden University Medical Center, Leiden, The Netherlands; ${ }^{\mathrm{b}}$ Institute of Neuroscience, \\ Université Catholique de Louvain, Brussels, Belgium
}

\section{Key Words}

Sukhanov · Van Gehuchten · History of medicine

\begin{abstract}
In 1898, Russian physician Sergey Alexeevich Sukhanov (1867-1915) spent a 3-month traineeship in Professor Arthur Van Gehuchten's anatomy laboratory in Louvain (Belgium). A folder containing 17 handwritten documents in Russian was recently discovered in the archives of the Museum of the History of Medicine, First Moscow State Medical University. The letters give a lively account of Sukhanov's everyday observations, experiences and opinions while he was in Van Gehuchten's lab. We took a selection of these notes and put them into medical and historical context.
\end{abstract}

\section{(c) 2016 The Author(s)}

Published by S. Karger AG, Basel

Yesterday I arrived in Louvain. Walking along the street, I ran into Van Gehuchten. He took me to his laboratory in the Institut Vésale and asked me what I actually wanted to do. I explained that I would like to study the changes in neurons due to arsenic and lead poisoning. On the whole, the most striking thing I found in the laboratory is the extraordinary courtesy of all the staff, from Van Gehuchten to the laboratory attendants.

So begins the first letter sent on 12 January, 1898, to Moscow by a Russian physician, Sergey Alexeevich Sukhanov (1867-1915; fig. 1). Shortly after completing his medical degree in 1891, Sukhanov began his career in the Mos-

\section{KARGER}

E-Mail karger@karger.com www.karger.com/ene

\section{(c) 2016 The Author(s) \\ Published by S. Karger AG, Basel 0014-3022/16/0756-0269\$39.50/0}

This article is licensed under the Creative Commons AttributionNonCommercial-NoDerivatives 4.0 International License (CC BYNC-ND) (http://www.karger.com/Services/OpenAccessLicense) Usage and distribution for commercial purposes as well as any distribution of modified material requires written permission. cow University Psychiatric Clinic, under the direction of Sergey Sergeevich Korsakov (1854-1900), founder of the Moscow psychiatric school [1]. Between January and April 1898, Sukhanov spent a 3-month traineeship in Arthur Van Gehuchten's laboratory in Louvain (Belgium). Arthur Van Gehuchten (1861-1914) was a biologist and physician, a professor of anatomy at the Université catholique de Louvain $[2,3]$. He had just published the second edition of his treatise on the anatomy of the human nervous system. This brilliant synthesis of the knowledge of his time had gained him international recognition.

A folder containing 17 handwritten documents in Russian was discovered in the archives of the Museum of the History of Medicine, First Moscow State Medical University. This folder includes 15 letters sent from Louvain to the Moscow University Psychiatric Clinic without a specified addressee and 2 postcards addressed to Korsakov (fig. 2). The letters give a lively account of Sukhanov's everyday observations, experiences and opinions while in Van Gehuchten's lab at the end of the 19th century - a kind of blog before the existence of the worldwide web. We took a selection of these notes and put them into medical and historical context.

The year is 1898, in the middle of the Belle Époque. Little Belgium has become one of the most important world industrial powers. In 1897, Brussels hosted a successful World Fair which was visited by more than 7 million people. The same year, the XII International Medical 


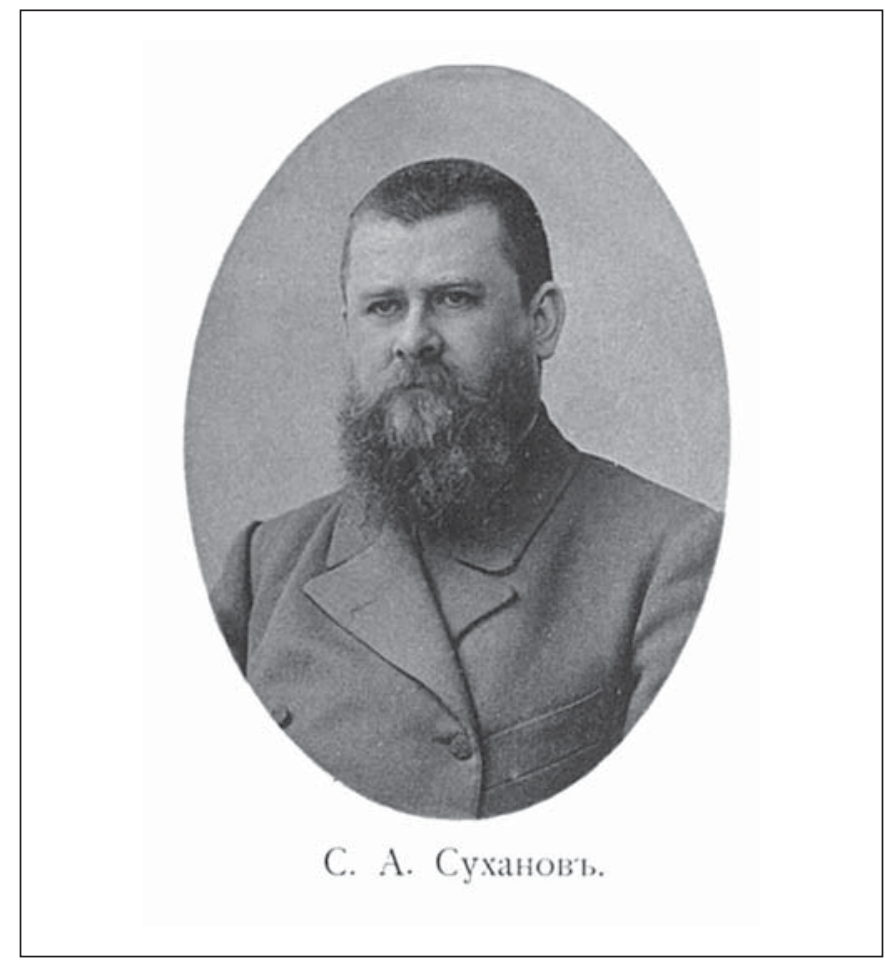

Fig. 1. Portrait of Sergey Alexeevich Sukhanov, courtesy of the Museum of the History of Medicine, First Moscow State Medical University.

Congress was held in Moscow, with an attendance of more than 6,000 participants from all over the world. The Congress President was Rudolf Virchow. Korsakov and Sukhanov were members of the organizing committee. It was during this congress that Korsakov presented a report 'On a special form of mental illness combined with degenerative polyneuritis' and the eponym Korsakov's syndrome was coined. The importance of this meeting is reflected by the coverage of this event in no less than 4 issues of the British Medical Journal [4-7]. The first of these reports mentions a lecture given by Professor Van Gehuchten on the finer points in the anatomy of the nerve cell. Van Gehuchten gave a second lecture at this meeting on the mechanisms of reflex movements (fig. 3). Van Gehuchten and other prominent European neurologists and psychiatrists were invited to visit 2 famous Moscow University departments: the Clinic of Nervous Diseases, headed by Aleksei Y. Kozhevnikov, and the Psychiatric Clinic, headed by Korsakov. All 45 foreign colleagues were made honorary members of the Moscow Society of Neurology and Psychiatry [8].

After his introduction to Van Gehuchten, Sukhanov immediately set to work.
For 3 days now, I have been attending Van Gehuchten's laboratory. My first impression has, however, not changed. Van Gehuchten is extremely agreeable, ready to help with my laboratory work. He is very active and open with everyone. All this makes it incredibly enjoyable. It would be difficult to find a more appropriate place abroad for the laboratory work on the subject in which I am interested. I have started the experiments already. Beside me, there is a cage with guinea pigs I injected with arsenic. Today I told Van Gehuchten that I would also like to study the human cortex to integrate this data into research on mental disorders. Tonight when I arrived at the laboratory, he joyfully announced that he could acquire 2 brains. He does not want to be paid for the costs I incur to his laboratory.

And a few weeks later, the following was the entry:

Recently, I produced a large number of preparations using Golgi's method for my other experimental work. Work at this laboratory is without doubt very useful for me. I have to admit that the microscope technique is much more sophisticated than what we have in Moscow. In order to learn what I encountered here, it is only necessary to devote a few weeks of practice.

In his new surroundings, Sukhanov also paid attention to equipment and technical procedures.

All the same there are a lot of novel things. In the laboratory, there are several devices that would be worth having at our clinic. I will probably send a catalogue of items you can buy in Brussels.

A few weeks later, he received a request from Korsakov for a particular microtome and he went with Van Gehuchten to a shop in Brussels to order it from Heidelberg and have it shipped to Moscow.

Sukhanov was in Louvain for barely a week when Van Gehuchten takes him for a very busy day in the capital.

Tomorrow I am going to Brussels for meetings of scientific societies - Medical Academy at 12 o'clock, Psychiatric Society at $2 \mathrm{pm}$ and Neurological Society at $5 \mathrm{pm}$. Actually, before attending those different meetings, Van Gehuchten took me to the outpatient clinic in Brussels where he has a small department for nervous diseases. While there, he photographed a case of child hemiplegia.

Indeed, Van Gehuchten's neuroanatomical work had led him to the study of medical problems, and he was developing a clinical practice in Louvain and in Brussels. He had always been very keen to use visual aids for his presentations, and from 1895 on, he adopted photography to illustrate his articles and lectures.

After lunch, we went by tram to the new university buildings, among them physical and physiological laboratories, where the Psychiatric Society meeting was held. Professor Héger gave a presentation on screen with an electric magic lantern of microscopic preparations at different magnifications, in the form of slides. The preparations with Golgi's method showed normal cerebral cortex as well as changes after experimental poisoning with morphine, 


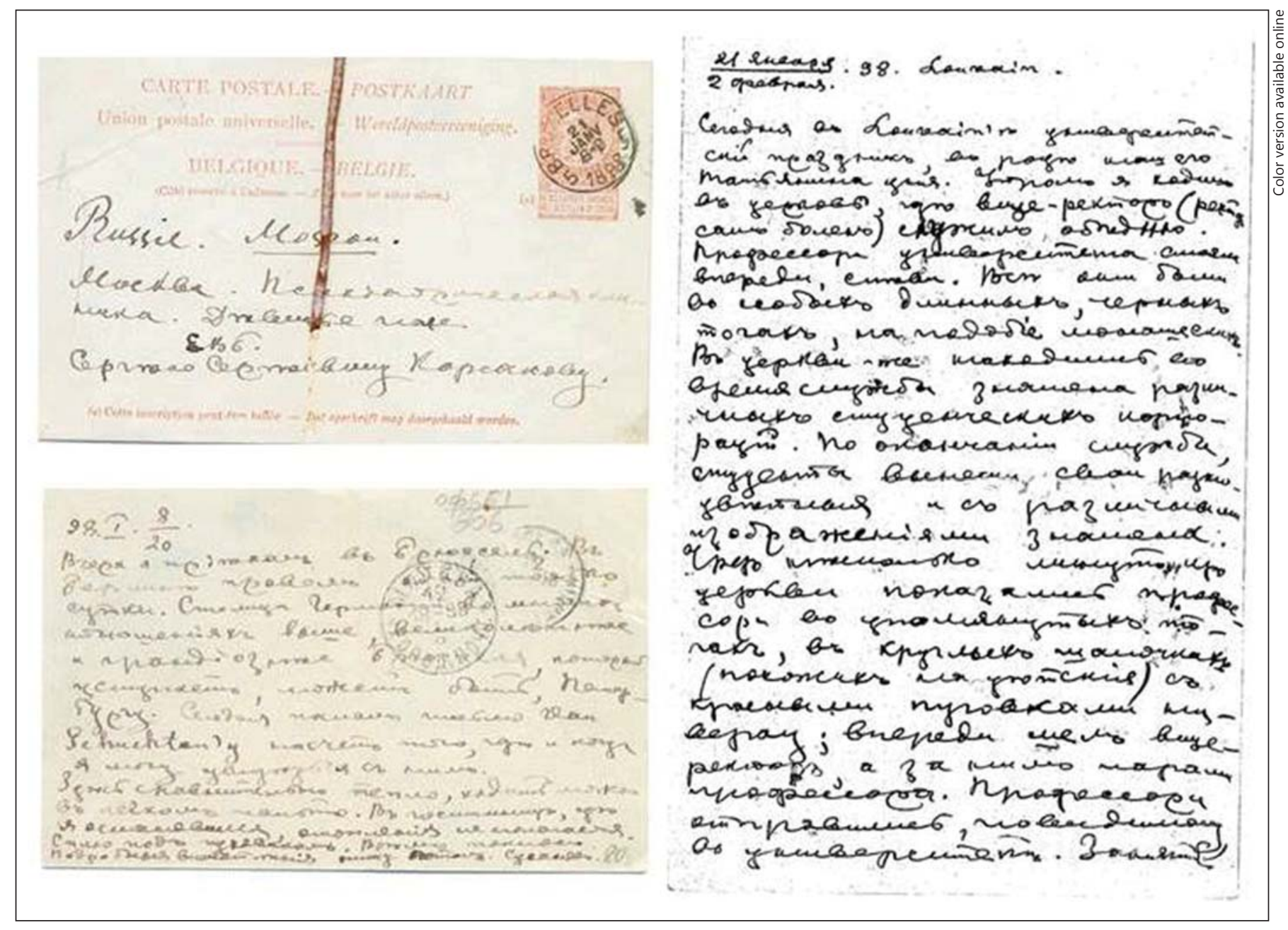

Fig. 2. One of Sukhanov's postcards to Korsakov and one of the letters sent from Belgium to Moscow in 1898, courtesy of the Museum of the History of Medicine, First Moscow State Medical University.

ether, etc. I must say that I saw many curious and interesting images. After this, we went to Héger's office, where microscopes with preparations were displayed. Here I saw changes in the cerebral cortex induced fairly easily as the result of simple scientific experiments, such as cooling animals. Changes appear in the form of very characteristic swellings with clear boundaries on the protoplasmic processes.

Indeed, under the impetus of the industrialist and philanthropist Ernest Solvay, who had a passion for science, several buildings had just been erected in order to create a real Citéscientifique, located in the Parc Léopold, in what is now the heart of the European area. Paul Héger (18461925), physician and physiologist, professor at the Université libre de Bruxelles, was the director of these science-oriented Solvay Institutes and was an ardent defender of experimental medicine.

Sukhanov observed several amusing things in Louvain.
Louvain is a small town with few cars. Everyone walks. There are very few cabs. But there are dogs harnessed to carts. They do not transport people, but food, vegetables and so on. As for Van Gehuchten, he likes to ride a bike. His wife too is a cyclist.

Indeed, the bicycle was an extremely popular vehicle in Belgium at the end of the 19th century. For women, it was considered a symbol of female emancipation.

Another particularly striking feature is that the locals wear wooden shoes, not only adults but also children. This makes strange sounds to our ears, when children released from school are running and playing in such clogs. Children here are quite noisy, singing while they walk along the streets, sometimes imitating student's songs, etc.

The contrast with Moscow seemed sharp. But this small provincial town proudly boasted of a university dating back to 1,425 - more than 300 years before the estab- 


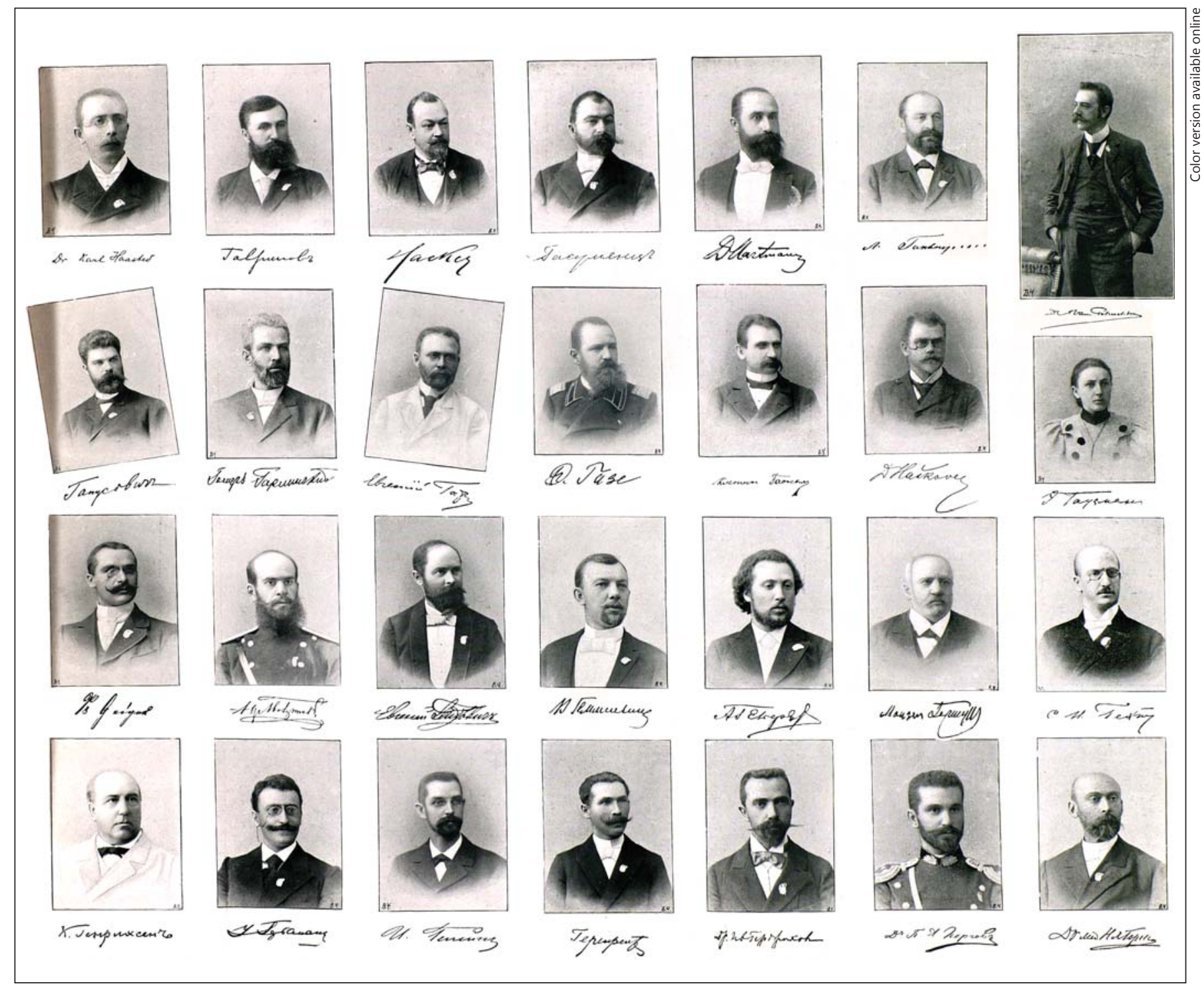

Fig. 3. Arthur Van Gehuchten (standing) among delegates to the XII International Medical Congress in Moscow. 1897, courtesy of the Museum of the History of Medicine, First Moscow State Medical University.

lishment of Moscow State University - and famous students such as Andreas Vesalius.

Through Sukhanov's observations, we take a glimpse into Van Gehuchten's daily routine and we penetrate the privacy of his laboratory.

Van Gehuchten is in the laboratory very often, not only in the early morning but also in the evening. He is rather good at conducting even very difficult scientific experiments. This particularly attracted my attention when he began doing a number of different experiments, mostly on rabbits and in large quantities. Van Gehuchten is very quick-moving, working very fast. He is enthusiastic and is not reluctant to do any of the dirty work in the lab.
He is not averse to singing. For instance, today while sitting at the microscope, he was singing some Flemish song. Typically after working at the microscope, he goes to the anatomical theatre, located only a few steps away although in another building, where he gives practical classes for the students.

Indeed, his anatomy professorship included daily early morning lectures complemented by afternoon demonstrations on the cadaver.

Last week, I started to attend Van Gehuchten's lectures. Now, with the start of the new semester, he gives a course in neurology. One of the 4 lectures a week begins as early as 7:45 am. I greatly enjoy following his lectures, which are very useful. I think that 
his course in neurology is pretty hard and difficult for the students to understand. His course is quite comprehensive and covers a lot more than is read at our university. Van Gehuchten speaks very quickly and uses a lot of scientific terminology in every lecture. He usually makes the preparations for the lecture himself, sometimes in the evening or in the morning before the lecture. Also he clarifies his presentation with drawings on the board. He draws rapidly and well. His lectures are attended by about 200 students.

When Sukhanov used the phrase 'course in neurology', he was referring to a course in anatomy of the nervous system, and not one of neurological diseases. Actually, it is only in 1908 that the first chair of neurology was opened in Belgium for Van Gehuchten. It is not the only time one is confronted with conflicting terminology. This reflects the somewhat loose definitions and boundaries of neurology and psychiatry at that time. To add to the confusion, when referring strictly to what we today call neurology, Sukhanov uses neuropathology. It is generally considered that neurological and psychiatric disciplines were clearly separated in Moscow in 1890, with Korsakov becoming head of a clinic exclusively dedicated to psychiatric patients. However, through our 21 st century eyes, the fact that Korsakov sent his young psychiatry assistant for a traineeship in the laboratory of an anatomist and histologist evokes an appreciation of biological psychiatry, even before the terms were coined.

During that March, Sukhanov visited Geel. In doing so, Sukhanov was following the example of dozens of psychiatrists from all over the world. This small Belgian town had centuries of long tradition with regard to treating the mentally ill as boarders in a family care system.

The doctor accompanying me invited me to go to a pub, where a patient is living with the owners. While we were drinking coffee, there was a gentleman sitting in the same room. He did not say anything nor did he pay any attention to us. This gentleman was the patient.

In the 19th century, Geel was considered - and still is a model of de-institutionalized psychiatric care. As such, it certainly had a great appeal to a pupil of Korsakov, himself a strong defender of a humane approach toward psychiatry.
As a result of his stay in Louvain, Sukhanov published 3 articles on experimental histological subjects in the Belgian Journal de Neurologie. He proceeded with a traineeship in Germany and in 1899 he defended his thesis on 'Protoplasmic processes of the cortex neurons'. On the recommendation of Korsakov, he was then appointed privat-docent at the Moscow University Psychiatric Clinic where he gave lectures on semiotics and diagnostics of psychiatric diseases. In 1907, he moved to St. Petersburg where he specialized in borderline psychotic disorders and involution psychoses. Sukhanov was a prolific author. His publications amount to some 225 papers and several books. Sukhanov's early works and his thesis were based on histological experiments started in Belgium (1897-1900). Later on, he published mostly on clinical psychiatry, was the author of various books and courses of lectures: Semiotics and diagnostics of mental diseases (1904-1905), Pathological characters (1912), Mental disorders (1914), Psychiatric Guidelines for doctors and lawyers (1914) etc. He was a co-founder of several Russian journals.

In 1912, the University of Louvain celebrated the 25th anniversary of Van Gehuchten's professorship. It was the occasion for a great ceremony at which scientists from all over the world gathered in Louvain to celebrate his achievements. The list of the members of the Honour Committee is impressive, with Cajal, Dejerine, Edinger, Flechsig, Golgi, Sherrington, Waldeyer, etc. More impressive still is the number of friends, colleagues and students, who contributed to his present, an oil painting portrait of the master. We find the name of Sukhanov on both lists.

Though the traineeships such as Sukhanov's were commonly undertaken in Europe of his time, Sukhanov's original comments on his visit, found more than a century later, give an additional historical insight and as a personal experience is of an evident interest.

\section{Disclosure Statement}

The authors declare no conflict of interest.

\section{References}

1 Vein A: Sergey Sergeevich Korsakov (18541900). J Neurol 2009;256:1782-1783.

2 Obituary: Professor Albert van Gehuchten. Br Med J 1914;2:1121.

3 Aubert G: Arthur Van Gehuchten (18611914). J Neurol 2001;248:439-440.

Sergey Sukhanov, a Russian Physician in Professor Arthur Van Gehuchten's Lab
4 The International Medical Congress, Moscow. Br Med J 1897;28:566-567.

5 The International Medical Congress, Moscow. Br Med J 1897;4:608-609.

6 The International Medical Congress, Moscow. Br Med J 1897;11:670-672.
7 The International Medical Congress, Moscow. Br Med J 1897;18:736-737.

8 Vein AA: The Moscow clinic for nervous diseases - walking along the portraits. J Hist Neurosci 2007;16:42-57. 